\section{Correspondence on 'Tumour necrosis factor inhibitors slow radiographic progression in patients with ankylosing spondylitis: 18-year real-world evidence'}

We recently read with great interest the article by Koo et al. ${ }^{1}$ In this retrospective study, the authors evaluated the effect of tumour necrosis factor (TNF) inhibitors on radiographic progression in patients with ankylosing spondylitis (AS) using real-world patient data with long-term follow-up information. They found that the TNF inhibitors could significantly impede the radiographic progression of AS patients. We commend the authors for performing this important study as the results could be very helpful in guiding practice in clinics. However, we noticed that the authors did not clarify the influence of TNF inhibitors on osteoporosis or vertebral fracture risk on imagings in the patients.

Osteoporosis is a commonly recognised problem in AS population, which can lead to serious consequences for the patients. For instance, patients with AS may have severe fractures and resulting neurological dysfunctions even after minor trauma due to osteoporosis. Similarly, AS patients may be vulnerable to have complications (such as instrumentation loosing and displacement) after surgery because of poor bone quality. Given the potentially dismal outcomes, it is highly imperative to aggressively treat the osteoporosis in AS patients. Currently, the effect of TNF inhibitors on osteoporosis in AS remains inconclusive. Previous studies have shown that osteoporosis or bone loss in AS are mainly caused by the inflammatory activities mediated by TNF-alpha. ${ }^{2}$ Considering that TNF inhibitors could effectively decrease the inflammatory response in AS, it is easy to speculate that TNF inhibitors may likely improve the osteoporosis of AS patients. In support of this, prior observations have suggested beneficial effects of TNF inhibitors on bone mineral density (BMD) at lumbar spine of AS patients, ${ }^{34}$ with infliximab, etanercept and adalimumab most commonly studied. However, most of these studies are observational cohort studies without long-term follow-up and control groups. In addition, impact of TNF inhibitors on hip BMD of patients is still unclear. ${ }^{4} \mathrm{~A}$ further comprehensive literature search revealed a lack of data with regard to the effect of other TNF inhibitors (including certolizumab and golimumab) on osteoporosis in AS. Moreover, studies have also demonstrated that TNF inhibitors fail to prevent vertebral fracture progression in AS patients. ${ }^{4-7}$ Therefore, according to these data available, we are still not able to determine the effect of TNF inhibitors on bone metabolism in AS. A recent systematic review and meta-analysis showed similar findings concerning this issue. ${ }^{8}$ Specifically, this study disclosed no strong evidence for TNF inhibitors in increasing BMD at hip and spine of AS patients. ${ }^{8}$ Given this situation, we recommend that more prospective and well-designed studies with appropriate sample size are needed to define the impact of TNF inhibitors on osteoporosis in AS. Noticeably, these studies should define the relationship between specific TNF inhibitors as well as their optimal regimen of administration (dosage, rhythm and duration) and osteoporosis in AS, considering that different drugs and administration methods may possibly have different therapeutic effects.

Published data have indicated that the osteoporosis in AS may also be attributed to other factors, such as age, menstrual status and pro-inflammatory interleukin-17 signalling. ${ }^{9}$ Considering these aspects, whether additional drugs should be prescribed in AS patients for osteoporosis amelioration deserves investigation.
Supporting this idea, a recent study evaluated the effect of a 2-year pharmacotherapy (combination of bisphosphonates and calcium/vitamin D supplements) on osteoporosis in AS patients and revealed a positive effect of this therapy on lumbar spine BMD of patients, ${ }^{10}$ similar to preceding findings. ${ }^{8}$ These preliminary data suggest an effective strategy to ameliorate osteoporosis in AS, although further confirmation is necessary. Importantly, this approach can also be further justified by previous reports showing bisphosphonates (including neridronate and pamidronate) as alone therapy or combination therapy with TNF inhibitors display beneficial effects on disease activity of patients with AS. ${ }^{11-13}$ Similarly, interleukin-17 inhibitors are also shown to be able to relieve symptoms and radiographic progression of AS patients. ${ }^{4}$ Evaluation of these drugs including those targeting other non-TNF mediated pathways (such as interleukin-6, JAKSTAT, CD20 and CTLA-4) on improvement in BMD of patients should be performed at present, as this result may impact the choice of osteoporosis treatment in AS.

\section{Zheng-Liang Zhang, ${ }^{1}$ Wei Huang, ${ }^{2}$ Guo-Hua Lv, ${ }^{3}$ Jing Li, ${ }^{3}$ Ming-Xiang Zou $\odot{ }^{4}{ }^{4}$ Zhi-Hui Dai ${ }^{1}$}

${ }^{1}$ Department of Orthopedics, Wenzhou Medical University Affiliated Dongyang Hospital, Dongyang, Zhejiang, China

${ }^{2}$ Health Management Center, First Affiliated Hospital, University of South China, Hengyang, Hunan, China

${ }^{3}$ Department of Spine Surgery, The Second Xiangya Hospital, Central South University, Changsha, Hunan, China

${ }^{4}$ Department of Spine Surgery, First Affiliated Hospital, University of South China, Hengyang, Hunan, China

Correspondence to Dr Ming-Xiang Zou, Department of Spine Surgery, First Affiliated Hospital of University of South China, Hengyang 421001, China; zoumx_spine@csu.edu.cn and Dr Zhi-Hui Dai, Department of Orthopedics, Affiliated Dongyang Hospital of Wenzhou Medical University, Dongyang 322100, Zhejiang, China; airdaizhihui@gmail.com

Contributors All authors contributed to drafting and revision of the manuscript.

Funding The authors have not declared a specific grant for this research from any funding agency in the public, commercial or not-for-profit sectors.

Competing interests None declared.

Patient and public involvement Patients and/or the public were not involved in the design, or conduct, or reporting, or dissemination plans of this research.

Patient consent for publication Not required.

Provenance and peer review Not commissioned; internally peer reviewed.

(C) Author(s) (or their employer(s)) 2020. No commercial re-use. See rights and permissions. Published by BMJ.

\section{Check for updates}

To cite Zhang Z-L, Huang W, Lv G-H, et al. Ann Rheum Dis Epub ahead of print: [please include Day Month Year]. doi:10.1136/annrheumdis-2020-218921

Received 19 August 2020

Accepted 21 August 2020

\section{S Linked}

- http://dx.doi.org/10.1136/annrheumdis-2020-218944

Ann Rheum Dis 2020;0:1-2. doi:10.1136/annrheumdis-2020-218921

\section{ORCID iD}

Ming-Xiang Zou http://orcid.org/0000-0002-4516-3917

\section{REFERENCES}

1 Koo BS, Oh JS, Park SY, et al. Tumour necrosis factor inhibitors slow radiographic progression in patients with ankylosing spondylitis: 18-year real-world evidence. Ann Rheum Dis 2020. doi:10.1136/annrheumdis-2019-216741. [Epub ahead of print: 13 Jul 2020].

2 Confavreux CB, Chapurlat RD. Systemic bone effects of biologic therapies in rheumatoid arthritis and ankylosing spondylitis. Osteoporos Int 2011;22:1023-36. 
3 Haroon NN, Sriganthan J, Al Ghanim N, et al. Effect of TNF-alpha inhibitor treatment on bone mineral density in patients with ankylosing spondylitis: a systematic review and meta-analysis. Semin Arthritis Rheum 2014;44:155-61.

4 Ashany D, Stein EM, Goto R, et al. The effect of TNF inhibition on bone density and fracture risk and of il17 inhibition on radiographic progression and bone density in patients with axial spondyloarthritis: a systematic literature review. Curr Rheumatol Rep 2019;21:20.

5 Beek KJ, Rusman T, van der Weijden MAC, et al. Long-Term treatment with TNF-alpha inhibitors improves bone mineral density but not vertebral fracture progression in ankylosing spondylitis. J Bone Miner Res 2019;34:1041-8.

6 Maas F, Spoorenberg A, Brouwer E, et al. Radiographic vertebral fractures develop in patients with ankylosing spondylitis during 4 years of TNF- $\alpha$ blocking therapy. Clin Exp Rheumatol 2016;34:191-9.

7 van der Weijden MAC, van Denderen JC, Lems WF, et al. Etanercept increases bone mineral density in ankylosing spondylitis, but does not prevent vertebral fractures: results of a prospective observational cohort study. J Rheumatol 2016;43:758-64.
8 Fitzgerald GE, O'Dwyer T, Mockler D, et al. Pharmacological treatment for managing bone health in axial spondyloarthropathy: systematic review and meta-analysis. Rheumatol Int 2020;40:1369-84.

9 Dubrovsky AM, Lim MJ, Lane NE. Osteoporosis in rheumatic diseases: anti-rheumatic drugs and the skeleton. Calcif Tissue Int 2018;102:607-18.

10 Arends S, Wink F, Veneberg J, et al. Bone mineral density improves during 2 years of treatment with bisphosphonates in patients with ankylosing spondylitis. $\mathrm{Br}$ J Clin Pharmacol 2020. doi:10.1111/bcp.14431. [Epub ahead of print: 12 Jun 2020].

11 Viapiana O, Gatti D, Idolazzi L, et al. Bisphosphonates vs infliximab in ankylosing spondylitis treatment. Rheumatology 2014;53:90-4.

12 Mok CC, Li OC, Chan KL, et al. Effect of golimumab and pamidronate on clinical efficacy and MRI inflammation in axial spondyloarthritis: a 48-week open randomized trial. Scand J Rheumatol 2015;44:480-6.

13 Toussirot E, Wendling D. Bisphosphonates as anti-inflammatory agents in ankylosing spondylitis and spondylarthropathies. Expert Opin Pharmacother 2005;6:35-43. 